\title{
The database right: Copyright and confidential information
}

Received: 22nd August, 2001

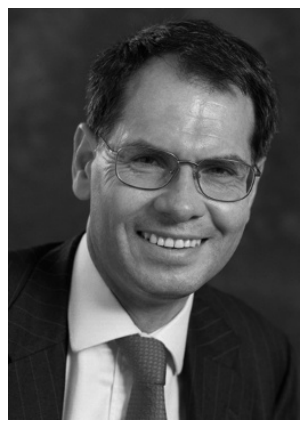

\section{Philip Westmacott \\ is a partner at Bristows and heads the firm's IT Practice. He specialises in intellectual property and has advised in the IT sector for over 18 years.}

\section{Harjinder Obhi}

is a solicitor in the intellectual property department at Bristows. He holds a PhD in physics and specialises in matters relating to IT.

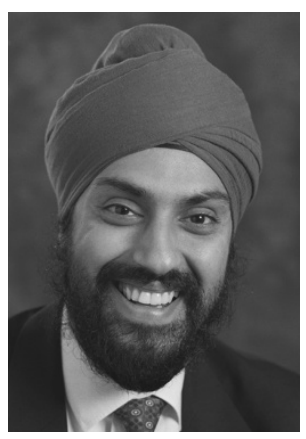

Abstract Databases lie at the very heart of the bioinformatics field. Traditionally, database owners have had to rely on copyright and confidential information rights to protect their databases. Database owners should find the current harmonised European approach to the legal protection of databases encouraging. Essentially, databases can be protected through copyright and a separate, recently introduced European intellectual property right called 'database right'. Creators of databases must, however, have sufficient nexus with Europe (actually the European Economic Area or 'EEA') in order to ensure that their databases qualify for protection under the new database right. Databases can also be protected under the law of confidentiality. This briefing paper outlines the position in the United Kingdom.

\section{DATABASES DEFINED}

The legal definition of a 'database' is quite broad: 'A collection of independent works, data or other materials arranged in a systematic or methodical way and individually accessible by electronic or other means'. Note that this includes a non-electronic database and that it is not necessary for the works, data or other materials to be physically stored in an organised manner. It is also important to realise that a computer program used in the making or operation of the database is not protected as a 'database' under database legislation (it could, however, be protected as a 'computer program' under copyright law, or if sufficiently inventive, it could be patented). Although the works, data or other materials in the database can be just about anything, a recording or an audiovisual, cinematographic, literary or musical work as such is excluded from the definition of a 'database'.

Once it has been established that there is the requisite collection of materials to constitute a database, there are two main ways in which it can be protected copyright and database right. It is possible for copyright and database right in one database to be owned by different people. Moreover, some databases may not be eligible for protection by both forms of intellectual property right.

\section{COPYRIGHT}

Copyright can only exist in a database that is sufficiently 'original'. A database is original if and only if, by reason of the selection or arrangement of the contents of the database the database constitutes 
the author's own intellectual creation. This is a quantitative criterion and no aesthetic or qualitative criteria should be applied. There is a baseline for originality: a compilation of several music recordings on a CD falls below that line because, as a compilation, it is not sufficiently original. It is clear that the structure and form of a database can be protected by copyright, even if there is no copyright in the individual items of data contained in the database. The originality requirement set out above must be satisfied, however. For example, where the author has expended some effort to arrange the contents to enable them to be easily searched and that arrangement is the author's own intellectual creation (in particular, it is not copied from elsewhere), then copyright would subsist.

The copyright owner has the exclusive right to carry out or to authorise the reproduction, translation, adaptation, arrangement, alteration, distribution, communication, display or performance to the public of the database. A lawful user of a database (eg someone who has acquired a licence to use it) is, however, allowed to do any of the above acts if they are necessary to enable him to access or use the contents of the database.

Generally, copyright lasts for the life of the author plus 70 years (and there are provisions covering joint and unknown authorship). If the country of origin of the database is not an EEA state and the author of the database is not a national of an EEA state, then the duration is that to which the database would be entitled in the country of origin (provided it does not exceed the period that would apply under UK law). Interestingly, there are provisions for databases generated in circumstances such that there is no human author. The author of such a computer-generated database is the person by whom the arrangements necessary for the creation of the database are undertaken. In that case, copyright expires 50 years from the end of the calendar year in which the database was made. Where a database is made by an employee in the course of his or her employment, then subject to any agreement to the contrary, the employer will own the copyright in it.

Member States of the European Union have the option to place restrictions on reproduction for private purposes, illustration for teaching or scientific research, use for public security or administrative or judicial procedure and any other restrictions which are traditionally incorporated in copyright under national law. In the UK, for example, there is a defence to copyright infringement called 'fair dealing'. Fair dealing covers things like research or private study, criticism and review, and the reporting of current events. Fair dealing with a database for research or private study is allowed provided that the source is indicated. The doing of anything in relation to a database for research for a commercial purpose, however, is expressly stated not to constitute fair dealing. The precise ambit of fair dealing may be amended by the implementation of the Copyright Directive in the UK.

\section{DATABASE RIGHT}

In 1996, a European directive introduced a new kind of intellectual property right called 'database right'. Member States of the European Union (including the UK, France and Germany) have now introduced domestic legislation implementing the new right. Importantly, there are geographical restrictions to qualification for database right. Database right does not subsist in a database unless, at the time it was made, its maker, or if it 
was made jointly, one or more of its makers, qualifies as one of the following:

- an individual who is a national of an EEA state or habitually resident within the EEA

- a body which was incorporated under the law of an EEA state and which has its central administration or principal place of business within the EEA; or which has its registered office within the EEA and its operations are linked on an ongoing basis with the economy of an EEA state

- a partnership or other unincorporated body which was formed under the law of an EEA state and which, at that time, has its central administration or principal place of business within the EEA.

If the database was made over an extended period, the above conditions must be satisfied for a substantial part of that period. The maker of the database is the person who takes the initiative and the risk of 'investing' (see below), and so sub-contractors are excluded from the definition of 'maker'. Where a database is made by an employee in the course of his employment, his employer is regarded as the maker of the database, subject to any agreement to the contrary. In relation to the second point above, it is thought that the generation of revenue and/or the payment of tax would help to show the requisite link between the registered office and the economy of an EEA state.

By way of contrast to the 'originality' requirement for copyright protection described above, for database right to exist, there must have been 'investment' in the creation of the database. In particular, there must have been qualitatively and/or quantitatively a substantial investment directed at obtaining, verifying or presenting its contents. Again, there is a minimum baseline for such investment before protection is acquired: a compilation of several music recordings on a CD falls below that line. 'Investment' includes spending financial resources and/or time, effort and energy.

The maker of the database has the right to prevent 'extraction' and/or 're-utilisation' of the whole or of a substantial part, evaluated qualitatively and/or quantitatively, of the contents of the database. 'Extraction' is the permanent or temporary transfer of all or a substantial part of the contents of a database to another medium by any means or in any form. Essentially, this means that for infringement by extraction there has to be copying (provided there is transfer to another medium).

'Re-utilisation' means making all or a substantial part of the contents of a database available to the public. Repeated or systematic extraction or re-utilisation of insubstantial parts may amount to extraction or re-utilisation of a substantial part.

Database right starts to run from the date of completion of the making of the database. It lasts for 15 years from 1st January following the completion of the database or, if the database is made public, for 15 years from the 1 st January following the date of first publication. If there is a substantial change to the database contents during this time (eg because of the cumulative effect of additions, deletions or alterations), the 15-year period starts again in relation to the 'new' database. The changes must result in the database being considered a substantial new investment (evaluated qualitatively or quantitatively). A substantial verification of the contents is sufficient. As the onus is on the maker of the database to prove that the database is 
to be regarded as a substantial new investment, it would be prudent to save database contents on a regular basis so as to create a comprehensive audit trail for future reference. It would also be useful to keep records of the investments (including labour expended) made by the maker and by others.

Where a database has been made available to the public in any manner: (a) a lawful user is entitled to extract or re-utilise insubstantial parts of the contents of the database for any purpose; and (b) the database right in such a database is not infringed by fair dealing with a substantial part of its contents if:

- the person who extracted it was a lawful user

- the extraction was for the purpose of illustration for teaching or research and not for any commercial purpose

- the source is indicated.

Owners of databases with genetic information continue to be able to rely on any existing copyright to protect their work. In addition, European-based bioinformatics enterprises will benefit from the extra protection afforded by the relatively new database right. Indeed, recent case law in the UK and the rest of Europe suggests that the new database right will be a potent addition to a business' portfolio of intellectual property rights.

\section{CONFIDENTIAL INFORMATION}

Another form of protection available to the owner of a database is provided by the law of confidentiality. This is a common law right entitling the owner to continued confidentiality of information which has been kept confidential. The 'owner' of confidential information may bring proceedings for breach of confidence where the confidential information has been used in an unauthorised fashion. In practical terms, however, by that time it may be too late as the information will often have been disclosed to the public and therefore no longer be capable of being protected as confidential information. An injunction may help to limit the extent of the disclosure and a claim for damages might be successful, but this may be little consolation.

If database owners wish to protect the contents of their databases as confidential information, the people with access to the database must be bound by confidentiality obligations. In the case of subscribers to the database, this will generally be achieved by incorporating confidentiality restrictions within the standard terms to which subscribers will sign up before accessing the database.

Although, in a sense, the intellectual property rights outlined above arise automatically, careful consideration and planning is required to ensure that they are preserved and can be used for commercial and enforcement purposes. 